DOCTRINA

\title{
Los dilemas de las tipologías de la democracia electrónica
}

\author{
The dilemmas of the typologies of electronic democracy
}

\author{
Jorge Francisco Aguirre Sala \\ Universidad Autónoma de Nuevo León, México
}

\begin{abstract}
RESUMEN La democracia electrónica (e-democracia), al ser motivo de clasificaciones, modalidades y tipologías, ha provocado varios problemas que pueden sintetizarse en el dilema general: ¿la versión electrónica de la democracia implica la transición hacia un régimen que supere los déficits gubernamentales, o los regímenes democráticos aprovecharán los aportes electrónicos para complementar la constitución de sus estructuras y el funcionamiento de sus instituciones, pero solo perpetuarán su estado y estructura actual? Establecer los dilemas de ambas partes, con una revisión histórica y una tipología de los modelos de e-democracia, es el objetivo de este análisis. Los resultados alcanzan argumentos para disolver los dilemas y aportar criterios para una taxonomía que explica las mutuas influencias entre las TIC y las demandas de la democracia.
\end{abstract}

PALABRAS CLAVE Democracia electrónica, modelos democráticos, participación política, transición.

ABSTRACT Electronic democracy (e-democracy), being the subject of classifications, modalities and typologies, has caused several problems that can be synthesized in the general dilemma: does the electronic version of democracy imply the transition to a regime that exceeds governments' deficits, or will democratic regimes take advantage of electronic contributions to complement the constitution of their structures and the operation of their institutions, but only perpetuate their current state and structure? Establishing the dilemmas of both parties with a historical review and a typology of e-democracy models is the objective of this analysis. The results reach arguments to dissolve the dilemmas and provide criteria for a taxonomy that explains the mutual influences between ICTs and the demands of democracy.

KEYWORDS Electronic democracy, democratic models, political participation, transition. 


\section{Introducción}

La inclusión de las nuevas tecnologías de información y comunicación (TIC) en la cultura ha hecho emerger la era digital. Este fenómeno cultural no ha sido ajeno al uso de las TIC en la política y sus aportes desde y para la democracia.

El surgimiento de la democracia electrónica - que podemos llamar e-democracia - ha dado lugar a un sinnúmero de interrogantes específicas. Quienes conciben la democracia principalmente como un procedimiento electoral, cuestionarán sobre los riesgos y ventajas del voto electrónico. Quienes ven en ella un sistema de representación del poder ciudadano en los agentes políticos, preguntarán hasta qué punto y de qué manera las TIC logran acercamientos entre los electores y sus gobernantes. Los interesados en una democracia de índole directa y participativa atenderán las maneras en que las TIC podrían introducir y favorecer nuevas modalidades de participación y deliberación. En paralelo a estas preguntas específicas, existen otras inquietudes generales: ¿es internet capaz de aumentar la calidad de la democracia? ¿Pueden las TIC transformar organizaciones políticas (parlamentos, instancias del Poder Ejecutivo, partidos políticos, plataformas de representantes, organismos autónomos) en instituciones más democráticas? ¿Las nuevas TIC son capaces de generar modalidades democráticas con capacidad autogestora — como la atribuida a la inteligencia colectiva o artificial- para superar sus propios déficits?

Del cúmulo de cuestiones posibles, han surgido inquietudes teóricas y prácticas referentes a las modalidades de la democracia que pudieran aprovechar los aportes de las TIC, además de sobre el modelo de democracia que podrían y — sobre tododeberían instaurar las TIC en la era digital. Por ende, de la abundancia y confusión que ocasionan las múltiples interrogantes, en este ensayo solo se pretende dar razón del nacimiento, análisis y disolución que presenta el dilema: ¿una nueva democracia generada por la era digital, o redes digitales al servicio de la democracia actual?

Para ello se pretenden los siguientes objetivos: i) manifestar en la introducción los objetivos, la pregunta general de investigación, las secciones del texto y los alcances y limitaciones temáticas; ii) establecer las razones de ambas partes del dilema; iii) elaborar una sucinta revisión histórica del estado de la cuestión y establecer una categorización de los modelos de democracia electrónica; iv) aportar argumentos para la disolución del dilema y precisar las correlaciones entre las funciones políticas, los mecanismos de participación ciudadana y las herramientas electrónicas, con el propósito de explicar las mutuas influencias entre las TIC y las demandas de la democracia; y v) arribar a conclusiones y señalar futuras líneas de investigación.

Ante estos propósitos, debe advertirse la multiplicidad de aspectos que quedarán pendientes: la evaluación histórica de los alcances de la democracia electrónica en la realpolitik; la didáctica requerida para una «ciudadanía digital»; las objeciones que las propuestas de democracia electrónica enfrentan ante los poderes de facto; los usos 
contemporáneos de la tecnología para controlar a través del big data, los algoritmos web y la transgresión de los derechos digitales de privacidad; la viabilidad de transferir las mejores prácticas electrónicas a diversas escalas políticas; y, por supuesto, la evaluación social de los impactos no deseados de la democracia electrónica, como el solucionismo tecnológico, el debilitamiento de las mediaciones institucionales, la cooptación o atomización de los usuarios y la erosión del capital social por las noticias falsas, la polarización, el discurso de odio, las cámaras de eco, los bots y el «efecto burbuja», entre otros.

\section{Los dilemas para clasificar la democracia electrónica}

Después de la emergencia de las TIC en la arena política, reconocidos análisis (Hindman, 2009; van Dijk y Hacker, 2018) muestran que los manejos del poder en los regímenes democráticos no presentan diferencias sustanciales entre las prácticas tradicionales y las incursiones políticas de las TIC. Por ende, el principal reto para lograr una buena e-democracia no parece radicar principalmente en la parte de la «e», sino en lo que corresponde a la democracia. La atención se centra en nuevas propuestas de democracia (en la estructura de sus modelos o en sus procedimientos, o en ambos), tanto para los niveles locales, nacionales en América y Europa y a escala de la Unión Europea, como para los partidos políticos, los parlamentos y otros actores de Gobierno. Pero los análisis constataron que las distintas variantes de la democracia también determinan y delimitan la inclusión de las TIC en las estructuras gubernamentales. Ello pauta el dilema: o la era digital genera y exige una nueva democracia, o las redes digitales solo quedan al servicio de la democracia como hasta hoy se ha desarrollado.

Si se opta por la primera parte del dilema, entonces las preguntas capitales son: ¿qué modelos y modalidades de la democracia electrónica deben emerger como efecto de la expansión de la cultura digital y los medios electrónicos? ¿Cuáles son las estructuras, los procesos y los instrumentos de participación política que exige el amplio espectro cultural de la «e» de cara a la e-democracia? ¿Cuál es la capacidad de las TIC para modificar el funcionamiento o los principios operativos de los sistemas democráticos de manera que favorezcan la legitimación representativa o directa e introducir nuevas modalidades de deliberación, participación y negociación política?

En contraste, si se opta por la parte del dilema en que las democracias de facto definan los alcances y límites de la inclusión de la electrónica, entonces se asistiría a la mera adecuación de las nuevas TIC, en modo colaborativo o complementario, a los diversos modelos de democracia existentes. En esta segunda parte del dilema, las preguntas son: ¿qué aportes otorga la democracia electrónica a los procesos democratizadores? ¿En qué esferas políticas incide la democracia electrónica en mayor medida?

Las preguntas que ambas partes del dilema deberían abordar son: ¿la democracia electrónica incrementa la calidad democrática? ¿Lo hace en cualquier modalidad? 
Pero ello solo se puede abordar desde la resolución de la cuestión base: ¿se genera una nueva democracia por y para la era digital, o las redes digitales quedan solo instrumentalizadas para la democracia? Es decir, ¿la versión electrónica de la democracia implica la transición hacia un régimen que supere los déficits gubernamentales, o los regímenes democráticos contemporáneos aprovecharán los aportes electrónicos para complementar la constitución de sus estructuras, junto con el funcionamiento de sus instituciones y procedimientos, de modo que solo perpetuarán su estructura actual?

Existen otros planteamientos sobre los modelos democráticos de la democracia electrónica recurriendo a perspectivas teóricas que delinean trayectorias diversas, incluso gráficas. Así, por ejemplo, Kurban, Peña-López y Haberer (2016) y Corval (2010), entre otros, han propuesto las perspectivas «desde arriba» $\mathrm{y}$ «desde abajo». En la primera, los Gobiernos, las instituciones políticas y los representantes de los ciudadanos usan e implementan instrumentos electrónicos para sus propósitos dentro de los espacios políticos democráticos tradicionales. Es decir, desde la existencia previa de estructuras, instituciones, instrumentos de participación política o ciudadana y procedimientos de gestión, se convoca a ser uso de los aportes informativos y comunicativos de la electrónica. Esta condición posee un mayor sesgo descriptivo de la democracia. Es decir, refieren de facto algunas modalidades democráticas y narran cómo estas incorporan, para sus propósitos, las herramientas electrónicas. Se trataría, entonces, de generar una red digital en auxilio de las estructuras políticas ya existentes. En la perspectiva "desde abajo», desde los movimientos sociales y el ciberactivismo, la ciudadanía - organizada o no-procura hacer emerger modalidades y modelos, procedimientos e instrumentos de democratización. Sin duda, estas circunstancias poseen una visión más prescriptiva o normativa de lo que debería ser la democracia. Por tanto, en su inicio, resultan ejercicios aspiracionales cargados de postulaciones y, en algunos casos, poseen rasgos idealistas que, en cierta medida, han sido evaluados como utópicos.

No puede decirse que, en todos los casos, entre la perspectiva «desde arriba» y «desde abajo» haya una correlación con los enfoques «pesimistas» y los «optimistasutopistas», que es abundante en la literatura sobre la democracia electrónica.

Por otra parte, al aceptar que el medio es el mensaje, cabría inclinarse por la idea de que los instrumentos (en este caso, las TIC, el ecosistema de la «e» y los instrumentos de participación política) son los que deberían estructurar a los procedimientos y los modelos de la política, no que la estructura o estándares políticos, incluida la democracia, sean los que limiten a los procedimientos e instrumentos para construir la voluntad general y discutir y aplicar las decisiones correspondientes para satisfacer dicha voluntad en la esfera pública. Es decir, la cuestión sobre desde dónde se construye la agenda política es vital para la correlación entre la calidad de la democracia y la calidad de la ciudadanía. Por ello, Coleman y Norris (2005: 32) advirtieron con una metáfora gráfica el doble sentido de la e-democracia: «La democracia electrónica 
es de arriba hacia abajo y de abajo hacia arriba; se trata tanto de los procesos institucionales de las jerarquías como de los arreglos más fluidos de las redes». Todo parece indicar que la suerte final de la «e» se haya en el kratos, en el demos y las recíprocas influencias entre los tres, aunque no siempre logren la simetría.

Compartimos el categórico juicio evaluativo de Sartori (1987: 443) respecto a la formulación de diversas clasificaciones y categorizaciones sobre los modelos de la democracia: «Una construcción artificial que me parece distorsionante». Distorsión que también está vinculada a la cultura digital y las versiones electrónicas que se relacionan a democracias de muchos tipos: delegativas, cosmopolitas, liberales, republicanas, radicales, pluralistas, elitistas, participativas, directas, agonales y un larguísimo etcétera. En estos casos, como en muchos otros, la democracia padece lo que Baratta (1997: 83) decía de la criminología: «Que los adjetivos terminarán estrangulando al sustantivo». También sufre lo que García Canclini (1995: 21) apuntó sobre la ciudadanía: «Defender la existencia [...] de una ciudadanía cultural, y también de una ciudadanía racial, otra de género, otra ecológica, y así podemos seguir despedazando la ciudadanía en una multiplicidad infinita de reivindicaciones». En efecto, no queremos estrangular ni despedazar la democracia, pero en gran medida deseamos reivindicarla a través de la democracia electrónica. El debate acerca de los diversos modelos de e-democracia es amplio, lo que obliga a una revisión sucinta de los principales aportes, no sin antes advertir la complejidad y dificultad de enfoques parciales y en muchas ocasiones sobrepuestos.

\section{El maremágnum de taxonomías sobre la democracia electrónica}

La variedad de clasificaciones — «distorsionantes», en los términos de Sartori- es amplía. Tan es así que Päivärinta y Saebo (2006: 818) quisieron liberar de la «jungla» de modelos a la democracia electrónica y reducir la cuestión al mínimo. Propusieron cuatro modelos: el liberal, el deliberativo, el partidista y el directo. Ellos se inclinaron por el modelo partidista y una mezcla de todas las modalidades.

Las propuestas más antiguas para hacer tipologías de la democracia electrónica fueron las de Hagen (1997): teledemocracia, ciberdemocracia, democratización electrónica; van Dijk (200o) propuso seis modelos: legalista, competitiva, pluralista, plebiscitaria, participativa y liberal, cuatro de ellos normativos y los demás descriptivos; Bellamy (2000) propuso: democracia de consumidores, demoelitista o neocorporativista, neorepublicana, ciberdemocracia; Vedel (2003) hizo una clasificación en distintas «edades históricas» de la democracia electrónica, coincidiendo en denominaciones con Hagen para la teledemocracia (para las décadas de 1970 y 1980, haciendo referencia a Amitai Etzioni, Benjamin Barber, Franck Arterton) y la ciberdemocracia (para las décadas de 1990 y 2000, haciendo referencia a Howard Rheingold, Alvin Toffler y Esther Dyson), pero anteponiendo en el tiempo la máquina de 
dirección (para las décadas de 1950 y 1960, haciendo referencia a Norbert Wiener y Karl Deutsch).

En la segunda década del siglo XXI, Dahlberg (2011), desde la retórica discursiva y las posibilidades de poner en práctica la democracia electrónica, consideró cuatro modelos: democracia liberal-individualista, deliberativa, de contrapúblicos — basada en Fraser (1990) - y el marxismo autónomo. Por otra parte, Fung, Russon-Gilman y Shkabatur (2013) propusieron seis modelos de interacción entre las TIC y la política: «la esfera pública musculosa», «aquí vienen todos», «democracia digital directa», «abogacía basada en la verdad», «constitución de las movilizaciones» y el «monitoreo social». Según van Dijk y Hacker, en el 2018 - con casi dos décadas de desarrollo y vigilancia del tema - tuvieron razones suficientes para insistir en los seis modelos que consignaron en el 2000.

La literatura en castellano presenta una primera generación que pasó revista hasta donde cronológicamente le fue posible (Cairo Carou, 2002; Cotarelo, 2002; Díez Rodríguez, 2003; Harto de Vera, 2006; Prats y Álamo, 2003; Subirats, 2002), comentando, repitiendo y evaluando en exposiciones sintéticas las versiones hasta aquí enunciadas. Las posteriores generaciones de habla hispana aportaron su propio resumen (Corval, 2010; García Guitián, 2016), con interesantes contribuciones - aunque no del todo clasificatorias ni con la misma hondura teórica o empírica-de Txopitea (2011), Feenstra y Casero-Ripollés (2014) y Ford Deza (2019), entre los más difundidos. Todos ellos surfearon entre prolijos gigantes como Castells e Innerarity y sus incansables e innumerables colaboradores. En casi todos estos estudios -así como en los que no abordan directamente el vínculo entre modelos de democracia y TIC - concluyen en términos generales la disminución del optimismo democratizador inicial o, de manera radical, en efectos neutros y negativos. Pero esta conclusión merece un texto aparte sobre la eficacia de la democracia electrónica en términos del ejercicio político y los derechos civiles.

En la literatura europea más reciente disponible hay autores (Lindner y Aichholzer, 2020) que contrastan las propuestas teóricas y las realidades empíricas por encomienda del Parlamento Europeo. En las propuestas teóricas enlistan varias aportaciones: democracia liberal, republicana o participativa y deliberativa, a las cuales añaden los modelos de van Dijk ya mencionados. En las descripciones de extracción empírica y con incipientes elaboraciones teóricas, discuten de manera somera la wikidemocracia y la democracia líquida (Lindner y Aichholzer, 2020: 21). Por otra parte, llama la atención que, a excepción de Lindner y Aichholzer, las modalidades de la wikidemocracia (Noveck, 2009) y la democracia líquida (Aguirre, 2019) no son estudiadas como propuestas apropiadas para postular o anidar la democracia electrónica, sin aportar un análisis argumentativo para desecharlas. Inclusive, la democracia líquida ha sido confundida con un software para ejercerla por medios electrónicos (Kersting, 2012: 48). 
¿Qué cabe hacer ante este maremágnum de elucidaciones y categorizaciones sobre la e-democracia? En primer lugar, considerar la declaración de Lindner y Aichholzer (2020: 15): «Podría decirse que las preferencias por un determinado modelo de democracia probablemente determinarán el tipo de la democracia electrónica que un proponente busca establecer». En segundo lugar, precisar esta declaración, porque hace emerger la principal ambigüedad que aquí se ha denunciado: o son los recursos de la nueva era electrónica los que pautan el deseo de un tipo inédito de democracia, o es un tipo a posteriori de democracia la que desea sujetar a la democracia electrónica. Así, los autores terminan por reconocer: «Entre las numerosas concepciones, se pueden discernir definiciones con un sabor normativo y otras más neutrales» (Lindner y Aichholzer, 2020: 16).

Päivärinta y Saebo (2006), como se ha dicho, quisieron liberar a la democracia de esta «jungla», y es menester reconocer el atinado trabajo de clasificación según los siguientes criterios: los modelos de democracia electrónica según quién establezca la agenda política (los ciudadanos o el Gobierno); los modelos según las clasificaciones teóricas previas o las descripciones empíricas existentes; y la ejemplaridad de casos de democracia electrónica reportados en estudios empíricos. Sin embargo, a catorce años de su aportación y tomando en cuenta los datos más relevantes a la fecha, cabe revitalizar la distinción de Blaug (2002), que también ilumina el dilema aquí planteado: concebir una democracia incumbent y otra critical. En la primera, las TIC solo conservarían y mejorarían las actuales democracias al canalizar la participación por las vías preestablecidas. Subirats (2002: 98) también visualizó este enfoque cuando exponía una alternativa: «Solo procesos de mejora y de innovación dentro del actual marco constitucional y político, característico de las actuales democracias parlamentarias». En contraste, en la segunda parte de la distinción de Blaug, la parte critical, como lo explica García Guitián (2016: 187): «[Las TIC] pueden ayudar a resistirse a la gestión y a dar un espacio a las voces excluidas que permita cuestionar las instituciones existentes».

En consecuencia, revitalizar las taxonomías de la democracia electrónica implica clasificar los modelos consagrados en la literatura según el enfoque del dilema aquí planteado. Por supuesto que una clasificatoria bajo las partes del dilema conlleva el riesgo de pasar por alto matices importantes, en que algunos modelos se emparentan, son coincidentes o parcialmente idénticos en algún proceso de participación por los diversos agentes que en ellos intervienen (ciudadanos, gobernantes, organizaciones de la sociedad civil, instituciones políticas, etcétera). Otro riesgo consiste en no advertir los desarrollos secuenciales o las circunstancias evolutivas que el alcance amplificador de las TIC ofrece a las democracias de facto. Es decir, el riesgo de no justipreciar los «progresos transicionales».

Como resumen, la tabla 1 detalla comparativamente los postulantes, estudiosos y denominaciones. Como se ha advertido, cualquier clasificación y categorización 
Tabla 1. Clasificatoria esquemática de los modelos de democracia electrónica bajo criterios prescriptivos o descriptivos

\begin{tabular}{|lll|}
\hline Autores & $\begin{array}{l}\text { Modelos prescriptivos } \\
\text { Transición a un régimen democrático más } \\
\text { deseable }\end{array}$ & $\begin{array}{l}\text { Modelos descriptivos } \\
\text { Incorporación de las TIC a democracias ya } \\
\text { establecidas }\end{array}$ \\
\hline Hagen (1997) & - Ciberdemocracia & • Teledemocracia \\
- Plebiscitaria & - Democratización electrónica
\end{tabular}

Fuente: Elaboración propia.

conlleva riesgos y, por ende, es discutible. Luego, en un intento de justificar la ubicación de cada uno de los modelos en la tabla, es menester hacer una descripción somera de los mismos. Esto supone un axioma inicial sobre qué ha de entenderse por e-democracia. Para ello, se postula la definición de Trechsel y otros (2004: 3):

La e-democracia consiste en todos los medios electrónicos de comunicación que habiliten o ayuden a los ciudadanos en sus esfuerzos por supervisar y controlar gobernantes o políticos sobre sus acciones en el poder público. Dependiendo de qué aspecto democrático se esté promoviendo, la e-democracia puede emplear diferentes técnicas: 1) mejorar la transparencia del proceso político; 2) facilitar la participación directa y la participación de los ciudadanos; y 3) mejorar la calidad de la formación de opinión mediante la apertura de nuevos espacios de trabajo.

Esta definición apunta a fortalecer más la soberanía de cada ciudadano que a robustecer un sistema político estatal, debido a las tres técnicas propuestas. No se trata entonces de adoptar una posición entre la democracia electrónica «desde arriba» o "desde abajo», sino en advertir entre una democracia más centrada en los ciudadanos que en las instituciones. La cuestión de qué sea la democracia electrónica y cuál ha sido su desarrollo histórico puede saldarse al revisar una aportación reciente (Aguirre, 2020), en que extensamente se han explicado los detalles de su génesis y se advierte que no todas las descripciones pertenecen propiamente a la «era digital», aunque se consideran bajo la misma fórmula: aportes o propuestas que las TIC, en 
contraste con los medios de comunicación masiva tradicionales, hacen respeto a la democracia.

En lo que respecta a las democracias descriptivas, la teledemocracia constituye un buen ejemplo de los aspectos transicionales, tanto tecnológicos como políticos. En la transición tecnológica, la democracia pasó por la radio, la televisión abierta y la televisión por cable entre los años 1939 a 1990. La transición política, en contraste, fue menos afortunada, pues transitó del optimismo - al vislumbrar una posible transformación de la democracia representativa hacia la directa-, con dirección al escepticismo y el pesimismo: entre 1990 y 1995, la expansión de las computadoras personales compatibles y la coronación de la accesibilidad a Windows e internet en 1995 consumaron la desilusión de la participación. La transición política no se consumó en la democracia directa, como el gran imaginario social había deseado a partir de las acciones comunicativas de Roosevelt y Perot en Estados Unidos, y la posibilidad mundial de navegar en Google desde 1998.

Por su parte, la democratización electrónica apunta al perfeccionamiento de la democracia representativa. Gracias a la comunicación mediante computadores, la era digital ayudó a superar los obstáculos técnicos informáticos y comunicativos, pero la dimensión política se quedó estancada en la estructura representativa, que a su vez quedó varada en la distancia entre los representantes y los representados.

Las democracias legalista y competitiva están ancladas en el modelo representativo. Van Dijk y Hacker (2018: 21-22, 202) solo las distinguen porque en la primera se enfatiza la separación de poderes y el balance entre gobernantes de la administración, las judicaturas y la representación, alegando que dicha división obliga a mejorar el intercambio de información entre los ciudadanos y los gobernantes o sus representantes políticos. En la segunda, el énfasis se pone en los partidos, sus líderes y los procesos electorales en que se da la competencia a través de las campañas que utilizan la electrónica para dotar de la información pública, hacer sondeos y guiar el voto. Las TIC, en efecto, pueden auxiliar a que todos los procesos informativos y comunicativos adquieran mayor eficacia, eficiencia, economía y autonomía dentro de los procesos democratizadores, pero la cuestión capital es la esencia y destino final del proceso democratizador. Cuando van Dijk y Hacker (2018: 21, 202) hacen notar que el modelo legalista y el competitivo principalmente están presentes en sistemas políticos con solo dos partidos, o sistemas presidencialistas, o espacios públicos liberales y populistas de derecha, conciben solo la modalidad democrática representativa. No en vano advierten (van Dijk y Hacker, 2018: xi) que la democracia digital no ha transitado más allá del modelo representativo y las TIC se estancaron en el mero complemento a las democracias existentes.

Las democracias de consumidores y demoelitista o neocorporalista, descritas por Bellamy, también están ancladas en el sistema representativo. El rol comunicativo de las TIC es útil para mejorar la representatividad, descentralizar las votaciones e incre- 
mentar la rendición de cuentas. Sin embargo, las jerarquías entre ciudadanos y representantes se conservan en una relación de verticalidad. Los estratos interactúan solo para dar mayor legitimidad a los gobernantes con la participación de los ciudadanos.

La democracia liberal, tanto en la descripción de Päivärinta y Sabeo (2006) como en la de Lindner y Aichholzer (2020) es vertical, representativa, competitiva y ajena al debate, a la deliberación y la construcción de capital social o sentido comunitario. Por ende, es individualista y promueve la indolencia del ciudadano privado ante las problemáticas públicas, pues considera que el cumplimiento de los procedimientos, los procesos y el respeto a las instituciones dotarán de suficiente poder y eficacia a los representantes políticos para enfrentarse y resolver los problemas. Las TIC son utilizadas para la competencia entre los actores de la esfera pública, para informar de la agenda gubernamental a la ciudadanía y dar paso a la consulta con el objetivo de hacer interactuar a los intereses en competencia. Bajo la tesis clásica del laissez faire et laissez passer, el Estado es un mero gestor de los asuntos generales, un conciliador de los asuntos individuales y el garante de los derechos privados.

La ciberdemocracia, tanto en la versión de Hagen como de Bellamy, resulta atractiva por su modalidad directa, su visión antiestatal o de control gubernamental minimalista. Postula el carecer de una identidad ciudadana fija que, si bien puede ocasionar multiidentidades con el riesgo de ser contradictorias, permite asumir tantos roles como la tecnopolítica lo permita. Su proclividad a generar comunidades - virtuales, progresistas, con sentido de apertura comunitaria, sin el «efecto burbuja» que en la actualidad se denuncia - y su horizontalidad no jerarquizada permiten evitar el centralismo y promover el debate, la discusión y las propuestas pautadas por mecanismos directos para gobernar. Las objeciones a este modelo no se hacen esperar desde la realpolitik y los obstáculos y resistencias que de facto presenta la pretendida organización y distribución equitativa del poder público. Esto abre una línea de investigación que no cabe en el espacio del presente texto: los pros et contra de la democracia electrónica, como se ha desarrollado en Aguirre (2018).

La democracia plebiscitaria expuesta por van Dijk y Hacker toma las decisiones sobre la vida pública a través de referéndums o plebiscitos. Por ende, es proclive al modelo directo y utiliza las TIC para dar soporte a dichos procesos. Según ambos autores este modelo es grato al populismo de izquierda (van Dijk y Hacker, 2018: 202). A pesar de sus bondades, es necesario recordar las cuestiones capitales planteadas por Päivärinta y Sabeo (2006): ¿quiénes definen la agenda política? ¿Quiénes y con qué medios convocan a las actividades participativas? ¿De qué manera se hacen transparentes y se rinde cuentas de dichas actividades y sus resultados? En resumen: ¿este modelo desplazará a quienes se encargan de oficio de organizar la totalidad de los procesos participativos y las ejecutorias legislativas y, sobre todo, sustituirá a autoridades administrativas y judiciales? Fung, Russon-Gilman y Shkabatur (2013) advertían que el desplazamiento de las organizaciones e instituciones tradicionales 
por la autoorganización o la gestión comunitaria facilitada a través de las TIC y la democracia directa, si bien puede ser deseable, es poco común.

En lo que respecta a la democracia pluralista, su modelo tiende a la descentralización. Al combinar los tipos directos y representativos, este último no es ejercido solamente por los representantes políticos, sino también por las organizaciones de la sociedad civil. Por ende, tiene rasgos del tipo liberal, pero no procede por mayorías, sino por la coalición de minorías cambiantes que trabajan para estar por encima de las decisiones que toma el Estado. Las coaliciones entre organizaciones de la sociedad civil obligan a procesos deliberativos y, por ende, el modelo posee un rasgo horizontal que, al hacer uso de las TIC, conlleva los riesgos de las divisiones y las polarizaciones.

La democracia participativa mezcla las modalidades directas y representativas enfatizando la información, la educación y la discusión colectiva, tal y como lo hace el modelo pluralista. Enfatiza la formación de la opinión pública y parece una versión social del modelo liberal que, por tanto, es bien visto por la izquierda populista.

La democracia libertaria - que no es la liberal y podría llamarse «democracia emancipatoria»- es descrita por van Dijk y Hacker (2018) como un modelo cercano al pluralista y al plebiscitario, pero especificando que el rol del Gobierno es más pequeño. Enfatiza la autonomía política de los ciudadanos para utilizar sus propias tendencias a la asociación, organización y capacidades de comunicación horizontal a través de las TIC. Ambos autores indican que, en su forma más extrema, este modelo considera a las instituciones políticas como obsoletas y que deberán ser superadas por una nueva realidad política colectiva creada en las redes (van Dijk y Hacker, 2018: 23).

Bellamy también propuso, dentro de los modelos prescriptivos, la democracia neorepublicana. Se avoca a la participación local con fuertes sesgos comunitarios que promueven el activismo y restablecimiento de la autonomía en la sociedad civil. El tamaño contemporáneo del demos no implicará ninguna dificultad ante las aportaciones de las TIC para llevar a cabo este modelo.

La democracia partidista propone que la agenda política sea controlada por los ciudadanos y que estos estén implícitos en la toma de decisiones. Si bien reconocen que no pueden señalar ejemplos que identifique el modelo o puedan nombrarlo, sí aceptan que existen casos reportados. Quizá lo primero pueda soslayarse con los estudios de Gerbaudo (2019) y los casos del Partido Pirata, el Movimiento Umbrella, el Movimiento 5 Estrellas y las múltiples experiencias mundiales del presupuesto participativo electrónico. Este modelo destaca porque los ciudadanos toman la agenda, pero no las decisiones, de manera que las TIC buscan la visibilidad ante la opacidad política de las élites. Este modelo debe convivir con el directo, deliberativo y el liberal, sobre todo porque en este último los candidatos a puestos de representación política informan a los ciudadanos y los ciudadanos cabildean a los candidatos.

La democracia directa, descrita por Päivärinta y Saebo (2006), no solo desea explicitar las decisiones políticas por los ciudadanos, sino que estos se apropian de la 
agenda para discernir qué asuntos deben tratarse y cuáles deben omitirse. No es desconocido que la democracia directa enfrenta muchas objeciones y abre la línea de investigación sobre los pros et contra de la democracia electrónica. No obstante, la tutela normativa o prescriptiva de este modelo alude al mayor requerimiento de innovaciones políticas que de novedades tecnológicas.

La democracia deliberativa remite a la esquematización del dilema aquí planteado: o las TIC exigen un modelo de democracia cuyo perfil es muy cercano al ideal deliberativo (por su naturaleza informativa, comunicativa, de debate, consenso y pacto), o la imperfecta práctica del ideal deliberativo (desde el ágora griega hasta las asambleas contemporáneas de cualquier escala y los equilibrios entre la soberanía individual y la popular) debe tomar todo recurso disponible de las TIC para alcanzar consensos y métodos de elecciones incluyentes. No obstante, la sucinta exposición de la democracia deliberativa debe finalizarse con una sabia estipulación que, por su valor, ha de citarse en extenso:

Aun cuando concediéramos que es importante que las personas deliberen antes de tomar una decisión (como creo que lo es), no siempre es indispensable que todos los participantes deliberen entre sí. Entre veinte mil sujetos no hay veinte mil puntos de vista diferentes sobre un tema, en particular si los ciudadanos votan después de haber discutido el asunto con sus próximos durante varios días, semanas o meses, o después de haber tenido oportunidades de observar con atención debates ilustrados entre personas expertas en los medios de comunicación de masas. Lo que quiero decir, en definitiva, es que si partimos de las premisas del ideal estándar, entonces, no podemos contener la deriva hacia un sistema puro de democracia directa electrónica (Linares, 2019: 56).

En otras palabras, las modalidades de la democracia electrónica que contemplan la deliberación no corren el riesgo de «bloqueo legislativo que se produciría si millones de personas presentaran alternativas individuales a un proyecto de ley», como ha supuesto Pérez-Luño (2014: 31), pues, en efecto, millones de personas pueden presentar alternativas individuales, pero al tratarse de un asunto o tema, los puntos a favor y en contra, independiente del origen múltiple de dónde vengan, tendrán un límite razonablemente manejable. Las razones en pro y contra no son millones, aunque sus emisarios lo sean.

La wikidemocracia es una propuesta de Noveck (2009) en la cual el rol de internet y un «software cívico» se conciben para establecer modos y procedimientos de participación altamente descentralizados aun dentro de un sistema representativo. Este modelo supone que los ciudadanos obran como pares, involucrados en múltiples redes, con propósitos de apoyar la construcción comunitaria, la colaboración y la co-creación, en una versión liberal y libertaria de la democracia. No obstante, esta propuesta se enfrenta al problema social- político de la desemejanza real entre 
los ciudadanos, pues las restricciones empíricas de los participantes no garantizan la igualdad política. También se enfrenta al problema comunicativo de garantizar la protección y privacidad de los datos de cada ciudadano.

Como puede conjeturarse, la wikidemocracia y la democracia líquida, al igual que la ciberdemocracia, se hallan ancladas en la posición de establecer una democracia propia para la era digital, con una trayectoria prescriptiva hacia la transición de un régimen democrático más deseable gracias a las intervenciones de las TIC. Ello exige aclarar la similitud y deslinde con los procesos democratizadores emergentes en internet.

Ahora bien, las novedades y bondades de la era digital no crearon el modelo de la democracia líquida, sino que lo posibilitan en la medida que sus obstáculos técnicos son superados gracias a las nuevas TIC. La democracia líquida tiene una denominación referencial con las descripciones de Zygmunt Bauman (2000) sobre la modernidad, al coincidir con la condición de efímero, frágil, vertiginosa o versátil. Ciertamente, lo «líquido» hace alusión a lo versátil, pero no necesariamente a algo frívolo, banal o del todo frágil. No obstante, aunque Bauman utilizó el adjetivo líquido desde el año 2000, el primer registro aceptado para democracia líquida no pertenece a Bauman. Procede desde mediados del año 2000 de un blog que ya no está vigente, pero ha dejados vestigios (Kuhn, 2013: 26; Mendoza, 2015: 47). La adjetivación de líquida a este modelo democrático es contemporánea, pero la idea misma y su procedimiento (Ober, 2008), en tanto sustitución de los mandatarios por sorteo, puede rastrearse en la antigua democracia ateniense, a partir de las huellas arqueológicas del kleroterion (el instrumento distributivo de las identificaciones de los miembros de la asamblea), la pinakion (las tablillas de identificación) y el ekklesiasterion (el lugar de la asamblea) (Lang y McK. Camp II, 2004). Una versión, no tan lejana en el tiempo y sin mayor elaboración teórica como la versión contemporánea, se encuentra en la Comuna de París de 1871, en tanto modelo de gobierno autogestionario.

La democracia líquida posee tres modalidades (Aguirre, 2017; Blum y Zuber, 2016): i) el voto directo; ii) el voto vinculante ganado dentro del Parlamento en los espacios de los partidos, de manera que se desplazan las decisiones de los representantes partidarios por las de sus representados; y iii) el voto mediado por apoderados proxies (representantes independientes de partidos) ad hoc, en razón de la confianza que gozan por su experiencia y probidad, cuando cabe la participación de dichos independientes ad hoc en los parlamentos o en el Poder Ejecutivo. En los dos últimos casos, la delegación del voto está sujeta a revocatoria de mandato en cualquier momento del quehacer legislativo o ejecutivo. En sus tres modalidades, y en particular en las dos últimas, aspira a la amplia deliberación entre los miembros del demos. En la tercera modalidad, la deliberación es útil para decidir, ratificar o rectificar la elección de los apoderados proxies. Para ello, se vale de la inclusión de internet como instrumento idóneo para la rendición de cuentas y propiciador la comunicación. 
La virtualidad de una asamblea ciudadana o un parlamento construido en la democracia líquida con las TIC no solo hace referencia a su condición tecnológica o de estadía «en la nube» - para utilizar una expresión contemporánea del vocabulario web-, sino que también apunta a la vertiginosidad — de ahí la adjetivación de líquida para esta democracia-, en el sentido de la corta condición de permanencia temporal de los agentes expertos, pues en esta propuesta normativa se encuentran permanentemente sujetos a la revocación de mandato.

En pocas palabras, la democracia líquida - en su versión electrónica- propone la deliberación, y al final de esta defiende el derecho de cada ciudadano a tener una aplicación electrónica para emitir su voto directo en el tablero electrónico de luces rojas y verdes que todavía hoy está dentro del recinto legislativo y en el futuro se hallará «en la nube» al determinarse como Parlamento virtual.

Como se ha señalado arriba, la democracia líquida fue confundida con un software para ejercerla por medios electrónicos (Kersting, 2012: 48). La confusión proviene de la marca alemana de servicios Interaktive Democratie, que ofrece cualquier aplicación del software Liquid Feedback. Este software es utilizado para la delegación líquida de votos por representación. El software no es una plataforma para la deliberación, sino una herramienta para la toma de decisiones. Por ende, debe quedar claro que si un grupo quiere deliberar sobre un tema, entonces se deben utilizar las plataformas de las redes sociales y no el software Liquid Feedback. Los creadores del software no creen que su producto pueda reemplazar la deliberación en vivo o en línea, pero lo aconsejan como complemento para la interacción entre personas afines en temas políticos.

Por otra parte, la democracia líquida no considera que la delegación de votos sea siempre necesaria, pues puede no serlo dependiendo del asunto que aborda. En el otro lado de la moneda, el software Adhocracy está diseñado para la deliberación, no para votar, aunque podría programarse para ello. Su capacidad también incluye funciones de edición colectiva para lograr un texto legislativo o un reglamento. Por medio de este software, los usuarios pueden conservar su anonimato, si así lo desean, y la identificación fuera de la plataforma o para acceder a ella no es un requisito.

De este modo, en la democracia líquida pueden utilizarse dos softwares, independientemente de sus versiones: uno para deliberar y otro para votar. Las votaciones podrían ser directas o para delegar la representatividad revocable en un proxy, y este, a su vez, en un proxy de proxies. Los softwares se anidan en plataformas electrónicas, pero constituyen solo las herramientas para ejercer los diversos procesos de la modalidad líquida. De este modo, la misma democracia líquida puede ser adjetivada de electrónica, directa, representativa, semidirecta, delegativa, mediada, revocatoria o plebiscitaria. 


\section{La superación de los dilemas}

Ante estos trazos generales del maremágnum de tipos de democracia desde o para la democracia electrónica, huelga reparar que la variedad de modelos se caracteriza por lo que Barber (1998) advertía al preguntar: «¿Cuál tecnología y cuál democracia?», pues, en efecto, las tecnologías son muchas y las variaciones de la democracia también son múltiples. Cuestión que Schudson (2006) amplió al declarar que no se puede generalizar la incidencia de las TIC en la democracia, porque hay varias modalidades de democracias. Lindner y Aichholzer aportan una razón de mucho más peso para objetar a cualquier pretendida generalización:

Si un promotor de la democracia electrónica pertenece a los partidarios de la democracia deliberativa, él o ella probablemente preferirá una mezcla de modos representativos y plebiscitarios [...] mientras que es probable que los miembros del campo liberal favorezcan formas de participación en línea que reflejen los principios de la democracia representativa (Lindner y otros, 2010: 14; citado también en Lindner y Aichholzer, 2020: 15).

Es decir, si la designación de un arquetipo de democracia para la e-democracia proviene de una previa inclinación por un tipo de democracia, entonces ese arquetipo se impondrá a priori a los modelos de la democracia electrónica. Es probable entonces que ello genere el decaimiento del optimismo digital desde la perspectiva que corresponde a la teoría del Estado, aunque los nuevos problemas de «la burbuja» digital, la polarización o «la manipulación desde algoritmos en la red» obedecen a razones empíricas distantes de los escollos que debe salvar la teoría política.

Päivärinta y Saebo (2006) y Weare, Musso y Hale (1999) tienen su propia explicación del escepticismo y el pesimismo: la investigación empírica de la democracia liberal, con el propósito de transformarla o revisarla a través de las TIC, aplica la normativa deliberativa al modelo liberal cuando este no promueve el modelo deliberativo. Es decir, se aplican criterios evaluativos hacia realidades de distinta índole. Justamente lo que había advertido Sartori (2003: 22) y de lo que cabe hacer hincapié: «Es un grave error cambiar una prescripción por una verificación». Estas explicaciones validan la mitad de la tesis que aquí se sostiene: se concibe la democracia electrónica y sus respectivas modalidades en función de qué tipo de democracia a priori a la cultura digital se desea promover. Debido a una estipulación así, no solo se concebirá el tipo de democracia electrónica que se desee para afianzar un sistema democrático, sino también la evaluación que obtendría ante los criterios de calidad democrática o de calidad de ciudadanía deseados limitaría el resultado de la evaluación (Kampen y Snijkers, 2003).

Esto revela una cuestión medular del asunto: la democracia electrónica pone en cuestión la institucionalización del uso de mecanismos de participación política a 
través de las TIC. Puesto que el uso de los medios de participación va desde la lucha por su construcción, reconocimiento y aplicación dentro de un marco jurídico institucionalizado, hasta la utilización efectiva por los ciudadanos con alto sentido del compromiso cívico para ejercer nuevas maneras de la distribución del poder público, la democracia electrónica no debe entonces concebirse «desde arriba» $\mathrm{o}$ «desde abajo», tampoco de manera "complementaria» o «revolucionaria», sino dando un giro a las fuentes tradicionales de la legitimidad. La democracia electrónica, de manera fluida y líquida, puede dar soporte a la conocida distinción de Scharpf (1999): una legitimidad «de entrada», que depende de los mecanismos que vinculen las decisiones en el sistema político con la voluntad de los ciudadanos, y otra «de salida», que depende de los resultados que efectivamente logran los trabajos de una común preocupación. En la primera se da la construcción de un nuevo modelo democrático o la reconstrucción de uno vigente por los aportes de las TIC. En la segunda, se reparten los efectos y la responsabilidad cívica entre los ciudadanos.

Por ende, la democracia participativa, deliberativa, inclusiva e incluyente anidará la e-democracia normativa y prescriptiva. Dará sesgos de ciberoptimismo o aspiracionales, con tendencias ascendentes con alto énfasis horizontalizador, cercanas a la democracia de índole colaborativa o frontalmente directa. En contraste, las democracias legalistas procedimentales, representativas y neocorporativistas apuntarán a perfiles descendentes y con tendencias a conservar variadas verticalidades, como el parlamentarismo, la declinación - mal llamada en ocasiones delegación-y los procesos electorales que oligarquizan a los partidos políticos. Huelga decir que existen instrumentos de las TIC para cualesquiera procesos de estos modelos y, por tanto, la variedad de enfoques para intentar apropiarse de la democracia electrónica.

Ahora bien, se afirmó que la e-democracia prescriptiva no necesariamente corresponde al modelo ascendente y que, de igual manera, la descriptiva no es la descendente, a pesar de la incorporación de la cultura digital en el espacio público y la esfera política. No obstante, vale la pena repasar las funciones informativas y comunicativas de las TIC en estos modelos. Para iniciar, es menester recordar el procedimiento habitual asignado a la democracia electrónica. Macintosh (2004: 3) distingue tres niveles de participación electrónica: el primer nivel es la e-habilitación o activación, que consiste en la capacidad ciudadana para el acceso, uso y comprensión de la información disponible en internet. El segundo nivel es el e-enganche, que tiene como propósito involucrar a los ciudadanos, principalmente a través de la consulta, con los actores de la política oficial (por esto, este enfoque podría guardar cierto aire de familia con el enfoque descendente). El tercer y último nivel es el e-empoderamiento, constituido por participación política para influir en la agenda y en la toma de decisiones. Como es notorio, la promoción inicial y el control transversal de estas actividades de participación podrían descansar en las autoridades convocantes y los ciudadanos estarían sujetos a las condiciones jurídicas que se hayan establecido para 
estos procesos. Entre las condiciones más importantes, están las maneras en que las autoridades incorporarían de manera final los aportes ciudadanos a las legislaciones o proyectos de ley y políticas públicas reglamentadas. Es de capital importancia, entonces, desde el establecimiento del tema y el inicio de una consulta, establecer cuáles son las condiciones de la convocatoria, el procedimiento y su respectivo desarrollo. Cabe esperar que un proceso así nazca desde las fuentes ciudadanas independientes, aun siendo un derrotero político distante de las modalidades de peticiones o iniciativas legislativas. Pero también podría nacer desde la actividad gubernamental con sus propias limitaciones; en ese caso, la mayoría de las propuestas se ciñen, más o menos, al mismo derrotero: convocatoria, discusión y toma de decisión.

Después de doce años de la explicación de Macintosh, Lindner, Aichholzer y Hennen (2016) distinguieron tres dimensiones generales de la e-democracia: la esfera pública (e-public) de temas de participación, la participación electrónica (e-participation) con variedad de formularios y la votación electrónica (e-voting). La participación electrónica posee sus propios niveles: información, comunicación y colaboración. En ellos surge el proceso de definición del problema, el establecimiento de la agenda, la toma de decisiones, la formulación de políticas, su implementación y su evaluación. Como es constante y notorio, estos derroteros pueden darse en forma descendente, con mayor control central del Gobierno, o en forma ascendente, con mayor prioridad en la actividad ciudadana. El Tratado de la Unión Europea de 1993 y el Tratado para el Funcionamiento de la Unión Europea de 2010 presentan estas ambigüedades. Pues, así como los artículos 10.3 y 11.2 del Tratado de la Unión presentan un modelo descendente, los artículos 11.2, 11.3 y 11.4 del Tratado y los artículos 17.1 y 24 del Tratado para el Funcionamiento presentan procesos ascendentes y en ocasiones horizontalizadores. Los ciudadanos europeos tienen derechos de participación directa, derechos de petición, derechos a que las instituciones les proporcionen espacios de diálogos horizontales y para establecer consultas. Pero también existen aspectos operativos de verticalidad que rompen tanto con la horizontalidad asamblearia como con los principios autoritarios de las jerarquías (Harvey, 2012). La democracia electrónica, a diferencia de los dos principios excluyentes de descenso y ascenso, permite formas de toma de decisiones que se articulan alrededor del principio de la transversalidad, de la delegación de confianza y de formas complejas de toma de decisiones que no pasan por el simple consenso asambleario ni por la democracia directa. Como, por ejemplo, la delegación líquida en proxies.

El Comité de Ministros del Consejo de Ministros de la Unión Europea para la democracia electrónica, en el corpus de sus Recomendaciones de 2008, señaló los 80 principios y 102 directrices para la e-democracia que también presentan la ambigüedad descendente o ascendente. Para dar evidencia de esto, a continuación se recopilan las comparaciones entre los principios y directrices que muestran dicha ambigüedad o la carencia de una posición entre el modelo representativo y el participativo o, 
lo que resultaría más grave aún, la insuficiencia de los matices y complementaciones de la interacción entre ambos modelos.

Desde el comienzo, en el Principio 2 se encuentra la asignación de un rol a la edemocracia: «La democracia electrónica es una de varias estrategias para apoyar a la democracia [...] es adicional, complementaria y vinculada con los procesos tradicionales». En pocas palabras, no se concibe como un modelo nuevo o un eslabón evolutivo más, sino como mera instrumentación al estatus ya alcanzado por la variedad de democracias existentes. Este comentario no constituye una interpretación forzada, pues el Principio 12 explícitamente declara: «La e-democracia puede ser aplicada con distintos grados de complejidad, en diferentes tipos de democracia y en diferentes etapas en el desarrollo de la democracia. No está vinculada y no da lugar a un tipo específico de la democracia». Si bien la estipulación del Principio 12 da lugar a que el Comité de Ministros no sea proclive hacia un modelo preconcebido de democracia para la e-democracia, tampoco ha lugar a concebirla como un nuevo modelo por sí mismo. Luego, ni siquiera nos encontramos entre Escila y Caribdis: la especulación normativa o prescriptiva y la indagatoria descriptiva sobre los tipos de democracia para la e-democracia - lo que aquí se ha expresado con el dilema «una democracia generada por y para la era digital, o redes digitales para la democracia»— queda completamente en el limbo, y parece que afecta más a la primera parte del dilema que a la segunda.

El Principio 21 del Comité del Consejo de Ministros reza que «la e-democracia en sí misma no afecta las obligaciones constitucionales y demás competencias y responsabilidades de los encargados de adoptar decisiones, sino que les puede proporcionar beneficios adicionales». Huelga decir que, cualesquiera fueran los beneficios referidos, es altamente cuestionable que la democracia electrónica no afecte obligaciones constitucionales, porque puede ampliarlas y puede crear otras nuevas. Las TIC dotan a las autoridades e instituciones de herramientas para cumplir obligaciones legítimas - aunque no siempre legalizadas-, como la rendición de cuentas y la transparencia. A los gobernados, quienes también son encargados de adoptar decisiones - al menos al votar o participar en campañas electorales-, los dotan de obligaciones al permitirles la participación ciudadana sin difundir noticias falsas, denostaciones o discursos de odio. Por no hablar de referéndums o plebiscitos, entre otros instrumentos de participación política - los mecanismos de acción política con reconocimiento jurídico- que no podrían ejercerse - o no se ejercían a cabalidad - sin las aportaciones técnicas que las TIC han proporcionado para superar sus obstáculos del tamaño del demos y la interactividad informativa y comunicativa.

Una medianía aparte de la ambigüedad descendente o ascendente está expuesta en el Principio 29, que reza:

La democracia electrónica puede reunir a los responsables políticos y los ciudadanos en las nuevas formas de participación y formulación de políticas. Ello puede 
conducir, por una parte, a una mejor comprensión de la opinión pública y las necesidades de la gente por los responsables políticos y, por otra, para una mejor comprensión pública de las tareas y desafíos que enfrentan los responsables políticos, y de este modo una mayor identificación del ciudadano con el sistema democrático y una mayor consideración a favor, y una mayor confianza en la democracia.

A primera vista, parecería que el Comité del Consejo de Ministros logra unificar y sintetizar las versiones descendentes y ascendentes; sin embargo, no es así. Lo que supone el Principio 29 es un modelo de democracia representativa que gracias a los apoyos de la e-democracia alcanzaría una mayor comprensión y acercamiento entre las partes que los déficits democráticos han puesto en conflicto. No muestra caminos, ni descendentes ni ascendentes, con tendencias horizontalizadoras ni vinculantes. Además, los Principios 35 y 36 refuerzan la estructura representativa, bajo la idea de mejorar las funciones democráticas de los representantes con los aportes de las TIC.

La ambigüedad de los principios del Comité del Consejo de Ministros es explícita en los renglones finales del Principio 36. Ahí se dice de la e-democracia: «Mientras que el e-Parlamento sustenta el principio de la democracia representativa, puede proporcionar herramientas para cambiar la cultura de la representación de tal forma que se garantice un desarrollo más inclusivo, la forma deliberativa y participativa de la democracia». En efecto, el Comité sustenta el modelo representativo y busca la oportunidad de inclusión y deliberación participativa, pero no parece abandonar el esquema vertical, ni siquiera en la estipulación del Principio 37: «Someter a votación la publicación de las leyes aprobadas por las asambleas generales». Es decir, visualiza la democracia refrendaria, pero no se aboca al abandono definitivo de la verticalidad con participaciones vinculantes, como lo muestran los Principios 41 y 42, que ponen más énfasis en los procedimientos comunicativos que en los fundamentos y consecuencias jurídicas de la participación política. El Comité no resuelve las tensiones entre las tendencias descendentes y ascendentes, lo cual queda explícito en la estipulación del Principio 43, al referirse a la e-consulta: «Sin que necesariamente obligue a quien debe actuar a conducirse de acuerdo con los resultados».

No obstante, el Principio 44 reconoce el poder de las iniciativas electrónicas para participar en el establecimiento de la agenda política. Aunque no por ello se alcance un ejercicio de democracia directa, pues los Principios 49 y 50 demarcan límites: «Mientras que la e-democracia depende de la moderna democracia, convenientemente adaptadas las TIC, la tecnología más y mejor en sí misma no conduce a una más y mejor democracia» y «la tecnología es un facilitador, no una solución». Ambas declaraciones, como muchas de las hechas por organizaciones internacionales de escala mundial, no son precisas. No hay ahondamiento sobre qué aspectos las TIC son facilitadoras, tampoco hay referencias precisas sobre las soluciones incapaces de alcanzar. Es decir, ¿qué facilita y qué entorpece la e-democracia? ¿Cuáles soluciones 
aporta y cuáles no consigue? Las áreas que no facilita o las tareas que no consigue, ¿requieren de mejores TIC, o de vincular a las TIC con las estipulaciones constitucionales y jurídicas, para que estas encuentren en las TIC la manera de operativizar su espíritu y no queden en mera letra muerta? No hay duda de que las TIC poseen pros y contras, pero ahora no se trata de la instrumentalización de las TIC, sino de la emergencia de un nuevo modelo e innovadoras prácticas de la democracia.

El Comité del Consejo de Ministros de la Unión Europea concibe una visión meramente instrumentalizada de la e-democracia para dejarla sometida al dominio de las instituciones gubernamentales. Así, por ejemplo, el Principio 53 refiere que «la responsabilidad de la tecnología utilizada corresponde a la institución a cargo de la herramienta e-democracia». Con lo cual queda estipulado, amén de que la edemocracia es una mera herramienta, que el ciudadano común no puede usar sus bondades más allá de los límites que imponga la institución gubernamental y, por añadidura, tampoco tendría una responsabilidad cívica del buen uso de las TIC. Se ha llegado al colmo de la antidemocratización cuando se tiene que solicitar autorización a las instituciones para poder hacer la política que es propia de la naturaleza de la polis. Parecería que la condición para que los ciudadanos participen es la anuencia de una ley de participación ciudadana, es decir, que la ley funda la participación en vez de que la participación sea el fundamento de las leyes. No es la estructuración democrática la que por sí misma deba poseer importancia primaria, sino que la estructuración obedece a la prioridad del ejercicio soberano de la ciudadanía para, en primer término, siempre salvaguardar la soberanía en la búsqueda del bien común.

La complejidad del equilibrio entre los procesos descendentes y ascendentes hacia una dirección horizontalizadora-democratizante se hace patente en los principios y las directrices del Comité europeo cuando se toma en cuenta el citado Principio 12: «No está vinculada y no da lugar a un tipo específico de la democracia» y la declaración del Principio 60: «La democracia electrónica puede ser introducida a fin de poner el énfasis en un tipo específico de la democracia o se define específicamente en los valores democráticos». Quizá parte de la problemática estriba en que el Comité desea abarcar todas las situaciones, aunque entre estas hay tensiones que las vuelven irreconciliables. Así, por ejemplo, el Principio 59, cuando dice: «La e-democracia puede ser introducida por cualquier interesado. Puede ser iniciada de arriba hacia abajo, es decir, por las autoridades públicas, en todos los niveles de Gobierno, o de abajo hacia arriba, es decir, por los ciudadanos. También puede ser de diseño horizontal».

A pesar de lo anterior, no se puede dudar de la capacidad humana, probada a lo largo de muchas eventualidades de la civilización, para armonizar, complementar, negociar y sintetizar propuestas disímiles de organización, del ejercicio del poder y la diversidad de intereses que motivan el proceder social y político. Tampoco cabe dudar de las posibilidades de encuentro entre los caminos democráticos descendentes y ascendentes, ni de sus mutuas posibilidades de reciprocidad y horizontalización. Sin 
embargo, es menester reconocer que la descripción de la e-democracia del Principio 59, si desea conservar su amplitud, debe conceder que la democracia cibernética y la democracia líquida constituyen los modelos a que corresponden tan exigentes deseos de la abundancia y versatilidad del manejo del kratos que anhela el demos en su totalidad. Luego, más que afirmar que la democracia electrónica está vinculada a uno u otro modelo de democracia, es necesario ceder al hecho de que la democracia misma exige su nueva versión en la e-democracia, tanto por el tamaño contemporáneo del demos, por el nivel cuantitativo y cualitativo de la información que requiere intercambiarse, por la calidad inteligible mínima de la comunicación y por el destino final de la racionalidad comunicativa en los consensos y la evaluación de los mismos toda vez ejecutados. El dilema se perfila hacia la solución: la e-democracia constituye el bastión de la cultura digital que implica la transición del poder público, en la escala política, hacia el régimen democrático que supera los déficits políticos padecidos a la fecha. No es un simple «solucionismo tecnológico», como denunció Morozov (2015), pues no se trata de una versión primitiva y llana en que se aplique la tecnología de las TIC a la política. Se trata, a todas luces, de la aplicación de la lucidez humana a la organización del demos - con su naturaleza comunicativa y desde su actividad hacia el esclarecimiento de la voluntad general- a través del granado aporte de las TIC para ejercer con excelencia el kratos.

No obstante la inferencia anterior, los principios del Comité europeo oscilan continuamente, como manifiestan los Principios 63 y 65. En el primero se encuentra: «La e-democracia prospera mejor donde hay la voluntad política y liderazgo para hacer que funcione con eficacia mediante la introducción de los cambios estructurales necesarios para tener en cuenta las opiniones expresadas. La incorporación de las TIC en los procesos democráticos por lo general requiere cambios estructurales y la reforma procesal». Es decir, de la era digital emerge una nueva democracia que cambia las estructuras. Mientras esto ocurre, el Principio 65 advierte: «El impacto de la e-democracia depende de la naturaleza democrática del Estado y las autoridades públicas, y la medida en que el respeto y la salvaguardia de los derechos humanos fundamentales y los derechos de las minorías y fomentar los procesos democráticos, incluyendo la participación política activa». Con lo cual se manifiesta la ambigüedad del dilema con una nueva cuestión: ¿primero es menester la naturaleza democrática del Estado (incluida la voluntad política de gobernantes y ciudadanos) y luego la e-democracia, o la e-democracia muestra las condiciones sin las cuales no puede fraguarse y consolidarse la verdadera democracia? Pero aquí no cabe la típica pregunta coloquial de si fue primero el huevo o la gallina, porque la distinción y advertencia de Sartori disolvió de manera definitiva el malentendido que se provoca al querer comparar y evaluar entre sí los niveles prescriptivos y los descriptivos.

Todo parece indicar que el Comité de la Unión Europea cayó en la trampa que advirtió Sartori. A esta advertencia puede dársele una imagen gráfica con la para- 
doja de Zenón de Elea. Zenón enseñaba que Aquiles jamás alcanzaría a la tortuga durante una carrera, porque la tortuga siempre aprovecharía en avanzar durante el tiempo que a Aquiles le tomaría cubrir la ventaja inicial que le concedió. Es decir, la democracia de facto, la del sentido descriptivo, del nivel del ser, nunca alcanzará a la democracia de jure, la del sentido prescriptivo, la del ideal del deber ser. A pesar de lo anterior, no caigamos en la falacia escondida que a su vez Sartori nos ha tendido al denunciar que las clasificatorias de la democracia producen trampas. Alcance o no alcance Aquiles a la tortuga, hay algo innegable: ambos avanzan. La democracia prescriptiva guía a la descripta y la práctica de esta inspira a ampliar las prescripciones de aquella; ambas proceden en mutua influencia. Esto disuelve el dilema y muestra que ambas definiciones operan sobre una línea transicional evolutiva que requiere vencer obstáculos y resistencias.

Un primer obstáculo es advertido por el Principio 71 del Comité europeo. En las tensiones de su conflicto interno, postulan: «Incluir, en el lado de la oferta, diferentes interpretaciones de la democracia». Pero no es aceptable un abanico oferente de democracias normativas que solo provienen de las experiencias prácticas. Cuando más, resultaría tolerable la iluminación que la práctica empírica aporta a la concepción humanamente limitada de la teoría política democrática. La razón estriba en que los intereses ciudadanos no son únicos, universales ni unitarios, y por ello deben seguir el principio de la justicia legal y subordinarse al bien común. La ciudadanía está, y muy probablemente seguirá, dividida en clases sociales y mantendrá muchos de los recelos que alberga antes de iniciar el proceso democratizador. Precisemos: los obstáculos pertenecen a las deficiencias de la teoría política, sobre todo cuando confunde la ley (lex) y el derecho (jus); mientras, las resistencias obedecen a las condiciones empíricas. Es decir, los ciudadanos pueden abogar por la multiplicidad de cosas que desean, pero ello no garantiza que sepan lo que necesitan cuando se trata de construir una voluntad general, incluyendo derechos diferenciales o categoriales, hacia el bien común. En definitiva, los riesgos de mal uso de las TIC - que, en efecto, son advertidos por el Principio 78 del Comité europeo-y del mal uso político - en parte advertidos por el Principio 72- son más graves cuando se corren entre las confusiones de niveles prescriptivo y descriptivo.

Toca el turno de pasar revista a las directrices el Comité europeo. La Directriz 2 obliga a tomar las perspicacias necesarias, pues cuando dice: «La tecnología no debe ser la razón o la fuerza impulsora para la e-democracia: las instituciones democráticas y los ciudadanos deben ser, y siguen siendo responsables de la e-democracia, sus procesos y herramientas», debemos advertir: si bien es cierto que los ciudadanos son la razón fundamental de la democracia y junto con sus instituciones deben responsabilizarse, el fundamento último de la democracia es el bien común. Las TIC no son, ni deben ser, el fin en sí mismo de la e-democracia, son un mero fin operis supeditado al fin operantis. 
Además, debe tomarse en cuenta el aspecto transicional. La Directriz 13 lo recuerda: «Conviene tener en cuenta la etapa del desarrollo de la sociedad civil, el nivel general y los medios de comunicación entre las autoridades públicas y otras partes interesadas, en particular a los ciudadanos, y el estado de desarrollo de la sociedad de la información el país en cuestión». Al tomar en cuenta el aspecto transicional, entonces puede adoptarse una actitud democratizadora para las Directrices 21 y 22. Respectivamente, dicen: «La introducción de la e-democracia debe implicar activamente, no eludir, las partes interesadas de la democracia tradicional» $\mathrm{y}$ «los políticos y los partidos políticos deben aprovechar la e-democracia con el fin de mantener $y$, si es posible, mejorar su papel esencial como "intermediario" en la democracia». No obstante, si no se adopta la perspectiva transicional, entonces las citadas directrices ubican la e-democracia como una mera dotación de redes digitales para las democracias existentes, lo cual provocaría un avance mucho menor en la evolución democrática. Evolución que ha de marchar hacia el bien común y no hacia la fetichización de la democracia por ella misma o por el mero uso de las TIC.

Entre las Directrices 23 a 49, el Comité europeo apela a la calidad de la ciudadanía debido a su disposición, capacidad y responsabilidad para actuar en las oportunidades de la participación política. Es bien sabido que la calidad de una democracia se establece por el número y frecuencia de instrumentos de participación política que posee. A la vez, la calidad de la ciudadanía se determina por la participación efectiva en dichos instrumentos. Los instrumentos o espacios de participación política, sin la acción de la ciudadanía, resultarían vacíos, y las acciones ciudadanas sin la estructuración jurídica de los instrumentos de participación serían caóticos. La mutua reciprocidad de ambas dinámicas (la calidad de la democracia si y solo si la calidad de la ciudadanía) debe hacerse presente en la e-democracia. Las Directrices 50 y 56 hacen referencia implícita a tal capacidad de respuesta de ambas partes en el marco de las e-peticiones, e-consultas, e-parlamentos y, por supuesto, la e-retroalimentación entre los agentes políticos. Entre otros aspectos importantes, es necesario insistir en explicitar cómo se incorporan al texto final los detalles alcanzados por consensos de mucha participación en las políticas públicas. La lógica de la política no debe ser reducida a una visión binaria descendente o ascendente, o a la dicotomía de mera aportación de las TIC a la democracia existente o la completa innovación de procesos democráticos por las TIC. Se deben considerar las mutuas implicaciones de cada agente en más de un sentido gráfico, pues cualquier acción de este enjambre —del carnaval democrático, como se ha dicho metafóricamente- debe impactar en ambos aspectos de la e-democracia, es decir, en la «e» y en el kratos de todos los usuarios electrónicos.

Entre las Directrices 72 a 102 se presentan más sesgos prescriptivos que descriptivos. Se atiende con amplitud a la dificultad empírica de la brecha digital y destacan las condiciones ideales de la Directriz 79: la voluntad política de gobernantes y ciu- 
dadanos. La Directriz 89 también destaca por reconocer el derecho a participar en la estructuración, funcionamiento, procedimiento y regulación de la e-democracia. Es decir, exhorta al uso de las redes digitales para lograr la transición desde la democracia tradicional hacia una visión generadora de una nueva democracia digital, que, en definitiva, resulta más participativa y directa.

Antes de pasar a la correlación entre las funciones políticas, los mecanismos de participación y las herramientas electrónicas, vamos a presentar una recapitulación tomando como guía las preguntas del dilema. Recuérdese la cuestión general: ¿existen modelos privilegiados de democracia en que habrían de insertarse los aportes tecnológicos electrónicos, o las nuevas tecnologías de información y comunicación generarán modalidades democráticas con capacidad autogestora para superar sus propios déficits? Como esta cuestión está enunciada en modo disyuntivo, habremos de advertir que por un lado se refiere a las democracias de facto y por otro a las versiones prescriptivas o normativas, es decir, a la democracia de jure.

Los modelos que parecen ser los más privilegiados a la caracterización prescriptiva o normativa son la ciberdemocracia de Hagen (1997) y la democracia líquida con sus tres modalidades. Ambos se caracterizan por las comunicaciones horizontales no jerarquizadas, por evitar la centralización comunicativa y política en instituciones o estructuras y por una dinámica de deliberación que pautan a los mecanismos directos de gobierno. Tanto la ciberdemocracia como la democracia líquida no eliminan la existencia de instituciones gubernamentales, sino que las proyectan fuertes en vez de rígidas, mucho más en el caso líquido. Una institución democrática rígida obedece a los mecanismos de representación que quedan fijos hasta los nuevos períodos electorales y cuyas consultas ciudadanas no son vinculantes, mientras un modelo de democracia fuerte implica el cumplimiento de las condiciones de participación ciudadana y política, que serían vinculantes y son obtenidas en diversas modalidades sin perderse en el anarquismo, las tentaciones de carecer de gobierno o la fragmentación jurídica que conlleva el riesgo de contradicciones legislativas. Por ende, las características deliberativas y el manejo transparente y ampliamente difundido de la información jurídica y de la jurisprudencia existente evitan la cooptación del poder por instituciones rígidas y potencializan la soberanía gracias a la educación en tecnopolítica. Además, el uso de sofisticados softwares que facilitan diversos métodos de consenso y votación, desde antaño estudiados y experimentados, permite un alcance general y diferenciado de consensos y obvian las dificultades comunes de la participación; en especial, la falta de efectos reales cuando los ciudadanos han hecho uso de la palabra.

Por ende, la cuestión de si las TIC generarán modalidades democráticas autogestoras para superar los déficits de la representación tradicional o de la opacidad en la transparencia y la rendición de cuentas, queda obviada: la nueva cultura digital, en la medida que apunta a la transición democrática, exige y ejecuta una información y 
una comunicación que a su vez postula una nueva democracia. El aspecto más ambicioso, entonces, es la transición y la final determinación de una nueva democracia que emerge de la cultura digital.

Respecto a la capacidad de las TIC para modificar el funcionamiento o los principios operativos de los sistemas democráticos de manera que favorezcan la legitimación representativa, e introducir nuevas modalidades de deliberación y participación política, el desenlace se observa por sí mismo: las TIC tienen capacidad democratizadora para dar legitimidad a la representación, no solo por la vía de la participación y la deliberación, sino por la capacidad bidireccional, también multidireccional, en que pueden establecer los vínculos de consenso entre los representados y entre estos y sus respectivos representantes. Las TIC, al estructurar modelos como la ciberdemocracia, la democracia líquida, la democracia participativa y la democracia libertaria, son de gran ayuda a los representantes, a los proxies, y en su momento también a los partidos, para conocer con claridad qué requieren los electores o qué desean, aunque ambos aspectos no siempre sean coincidentes. Por ende, las nuevas legitimidades que hemos llamado - tomando la denominación de Scharpf- «de entrada», a través de las tres entradas que proporcionan las modalidades de la democracia líquida y los softwares deliberativos y de votaciones conclusivas e incluyentes, permiten la legitimidad representativa y de elección. Pero, sobre todo, permiten una nueva democracia basada y exigida por la cultura digital que está sustentada en la responsabilidad cívica conseguida por la educación en tecnopolítica, es decir, la legitimidad «de salida».

Ante la cuestión de qué innovación política puede generarse a raíz de los cambios tecnológicos que supone la implementación de las TIC, cabe reiterar que la innovación apunta hacia una amplia demografía de legitimidad y la implementación de mecanismos de participación apegados a los derechos que consagran la democracia directa. Ello, sin los riesgos que antes de la cultura digital implicaba la llana soberanía de un pueblo que carecía de lo que Linares lúcidamente ha llamado «democracia participativa epistémica». Las TIC no solo interpelan la multidireccionalidad informativa, sino también la corresponsabilidad de la comunicación y de los consensos o acuerdos alcanzados por esta. Comunicarse, debatir y consensuar en política en gran medida es comprometerse. En el mejor de los sentidos, comprometerse con sinceridad y sin ánimo de consignas sesgadas, ajenos a la finalidad propia de quienes se comunican: la persuasión recíproca del interés común.

Si bien hasta ahora las respuestas parecen inclinarse por la parte del dilema que claramente concibe la e-democracia hacia nuevas estructuras y dinámicas de la democracia, ello no impide reconocer que hay dimensiones de la democracia electrónica que están en ambas partes del dilema. En el mejor de los casos, en una transición democratizadora deseable, a pesar de que pueda generar nuevas dificultades procedimentales. La pregunta sobre si la e-democracia aporta una mayor calidad democrática que cualquier otra modalidad, parece resolverse sin dificultad: la e-democracia, 
por su versatilidad, inclusión, capacidad de corrección y producción de capital social, aporta calidad democrática en la medida que la calidad de la ciudadanía se aboque a la participación con el uso sus instrumentos.

Por lo tanto, es legítima la duda que han abordado varios teóricos y que nosotros tampoco podemos dejar de lado: ¿se requiere primero un régimen democrático para instaurar una democracia electrónica? Desde la perspectiva que finca las dinámicas públicas en la voluntad política, la respuesta parece ser siempre afirmativa. Sin embargo, no resulta una conditio sine qua non que primero deba existir un régimen democrático para instaurar un nuevo modelo democrático. Nunca fue así en cada aparición histórica de la democracia. La dinámica transicional implica un conflicto y, sobre todo, una cultura cívica plétora de conciencia que impulsa a la acción. Requerir la democracia para poseer democracia es confundir los planos que Sartori advirtió como engañosos y caer una petitio principii. Más bien, los procesos de transición hacia la democracia electrónica apuntan una mediación a través de los partidos líquidos, como en su tiempo la aparición de los partidos políticos fue un paso hacia la democracia moderna. Los conocidos riesgos de oligarquización tendrían que salvarse por las características de horizontalidad que aportan las TIC desde la cultura digital. Si bien es cierto que estas características pueden ser contaminadas y minadas, su naturaleza presenta una resistencia, resucitadora como ave fénix, una y otra vez, a dar secuencia del derecho al voto y la autodeterminación, después de alcanzar el derecho de la voz comunicativa.

La cuestión sobre si primero debe lograrse un régimen democrático para después conseguir una democracia electrónica también conlleva tres aspectos transicionales.

El primero consiste en aludir al compromiso fuerte de una cultura cívica (sea nacida por la necesidad, la indignación o por la educación ciudadana). Es cierto que la cultura cívica requiere de líderes que la promuevan, de cierta administración organizativa o profesionalización y hasta de factores externos que la detonen, como las emociones políticas causadas por contingencias imponderables. No obstante, la cultura cívica constituye una política democrática, no un régimen democrático, y de ahí su condición de inacabada pero evolucionante.

En segundo lugar, se requiere un conflicto que enfrente las fuerzas establecidas (statu quo) y las de la resistencia y el cambio. Conflictos de esta naturaleza son provocados y liderados por disidentes y sujetos de condición avanzada que no desean dejar atrás a los ciudadanos más rezagados. Estos líderes, según Crane Brinton (1962), no provienen de las condiciones de clase más atrasadas, aunque se enfrentarán a la imposibilidad de movilizar al unísono a todos los aplazados, como lo advirtió Alfred Marshall (1997).

El tercer aspecto primordial es la necesidad de liderazgos negociadores y organizadores para establecer las reglas de transición y consolidación del siguiente eslabón democrático. La democracia electrónica, como cualquier proceso democrático y cual- 
quier proceso común al advenimiento de una cultura como la digital, está sujeta a prácticas de ensayo y error. Esas prácticas pueden oligarquizarse o democratizarse. En esa coyuntura, la lucha por el reconocimiento, el equilibrio de los poderes de facto y el hábito electrónico introducido como un caballo de Troya, juegan un papel primordial para no dejar que el modelo democracia electrónica quede como un simple agalma.

En la visualización de los procesos transicionales se ubican las preguntas de la parte dilemática descriptiva: ¿cuáles son los aportes de la democracia electrónica a los procesos democratizadores? La variedad de TIC a lo largo de las versiones web y las diversas generaciones de herramientas electrónicas aportan la idea de correlaciones entre los instrumentos «e» y los mecanismos de participación ciudadana de algunos procesos y procedimientos políticos. Las clasificaciones en funciones, tipos y herramientas de los procesos de participación electrónica han sido exhibidas por Macintosh, Coleman y Lalljee (2005) en las experiencias que pudieron ser analizadas desde 2005, hasta la clasificatoria de Lindner y Aichholzer en 2020 (2020: 23), pasando por las aportaciones de Molinari (2010). La tabla 2 pretende ser una síntesis de las aportaciones, análisis y clasificaciones de los medios electrónicos para la construcción del modelo de democracia electrónica. Debe considerarse que las plataformas electrónicas, las redes cibernéticas y los instrumentos de participación política seguirán cambiando. Por ejemplo, en el ámbito político, los parlamentos se «abrieron» a escuchar participaciones directas (open parliament, también o-parlamentos) para después, en el ámbito electrónico, instrumentalizarse como e-parlamentos. Sin embargo, como la historia ya lo demuestra, lo más probable es que muchos cambios no lo hagan en la dirección indicada por algunos vaticinios del pasado (Szoka y Marcus, 2010; Tsatsou, 2014).

De cualquier manera que evolucionen o modifiquen las herramientas electrónicas para incidir en los procesos de participación política, el común denominador parece insistir en acercamientos a la deliberación y a la potestad de actuar a través de instrumentos políticos de democracia directa o por medio de proxies que se instauran en las instituciones de representación o de mediación semidirecta. Las Directrices 50 y 56 del Comité europeo, como se ha dicho, apuntan reiteradamente a las e-peticiones, e-consultas, e-parlamentos y la e-retroalimentación deliberativa entre los agentes políticos. Por ello, la cuestión de, entre todas las posibilidades de incursión política, en qué procesos democratizadores incide la e-democracia en mayor medida, es una pregunta obligada. Las experiencias transicionales de las democracia de facto, es decir, los casos de democracias reales que apuntan a convertirse en ejemplaridades de las democracias de jure, normativas y prescriptivas, enseñan que la mayor medida de incidencia de la democracia electrónica se halla en los procesos micro - una iniciativa particular co-colaborativa en el quehacer legislativo o el presupuesto participativo, como los casos más recurrentes- y en aspectos en que destacan la deliberación y delegación distintas a la declinación. 
Tabla 2. Correlación entre herramientas electrónicas y mecanismos de participación política para la construcción de la democracia electrónica

\begin{tabular}{|c|c|c|}
\hline Funciones políticas & Mecanismos de participación & Herramientas electrónicas \\
\hline Dar y recibir información pública & $\begin{array}{l}\text { e-info, e-paneles, } \\
\text { e-quejas }\end{array}$ & $\begin{array}{l}\text { Correo electrónico, Twitter, blogs, Facebook, } \\
\text { Whatsapp, Instagram, Youtube }\end{array}$ \\
\hline Elaborar peticiones & e-peticiones, e-plebiscitos & Correo electrónico, blogs, Youtube \\
\hline Presentar y firmar peticiones & e-peticiones, e-plebiscitos & Correo electrónico, Twitter, Whatsapp, Youtube \\
\hline $\begin{array}{l}\text { Organizar convocatorias para } \\
\text { establecer temas de la agenda }\end{array}$ & $\begin{array}{l}\text { e-peticiones, e-plebiscitos } \\
\text { e-paneles }\end{array}$ & $\begin{array}{l}\text { Correo electrónico, blogs, Facebook, Whatsapp, } \\
\text { Youtube }\end{array}$ \\
\hline Promover consultas & e-consulta & Correo electrónico, Twitter, Facebook, blogs, Youtube \\
\hline Organizar discusiones deliberativas & $\begin{array}{l}\text { e-parlamento, 0-parlamento, } \\
\text { e-mediación, e-encuestas } \\
\text { deliberativas }\end{array}$ & Correo electrónico, blogs, Facebook, Twitter, Youtube \\
\hline Elaborar proyectos & $\begin{array}{l}\text { e-foros, e-iniciativas, e-presupuestos } \\
\text { participativos }\end{array}$ & $\begin{array}{l}\text { Correo electrónico; blogs; Youtube; softwares y } \\
\text { plataformas electrónicas como Reddit, Titanpad } 0 \\
\text { Loomio }\end{array}$ \\
\hline $\begin{array}{l}\text { Organizar campañas para } \\
\text { promover proyectos }\end{array}$ & e-campañas, e-foros & Correo electrónico, blogs, Twitter, Youtube \\
\hline Discutir proyectos & $\begin{array}{l}\text { e-paneles, e-foros, e-parlamento, } \\
\text { o-parlamento }\end{array}$ & $\begin{array}{l}\text { Correo electrónico, blogs, Facebook, Twitter, } \\
\text { Instagram, Youtube }\end{array}$ \\
\hline Votar proyectos & e-voto, e-referéndum & $\begin{array}{l}\text { Correo electrónico; Twitter; Youtube; softwares } \\
\text { participativos como AgoraVoting, Democracy 0s, } \\
\text { Liquidfeedback, Appgree, Adhocracy; aplicaciones } \\
\text { como VoteSwiper o Tuvoto.eu }\end{array}$ \\
\hline $\begin{array}{l}\text { Promover la preparación, } \\
\text { capacitación y talleres }\end{array}$ & $\begin{array}{l}\text { e-participación, e-deliberación, } \\
\text { tecnopolítica }\end{array}$ & $\begin{array}{l}\text { Facebook, blogs, Youtube, plataformas como } \\
\text { Blackboard }\end{array}$ \\
\hline Tomar decisiones & e-legislación, e-encuestas & $\begin{array}{l}\text { Youtube, softwares participativos como: AgoraVoting, } \\
\text { Democracy 0s, Liquidfeedback, Appgree, Adhocracy. } \\
0 \text { aplicaciones como: VoteSwiper, Tuvoto.eu }\end{array}$ \\
\hline Ejecutar decisiones & e-gov, e-justicia, e-referéndum, & Plataformas de eGov. \\
\hline Organizar la rendición de cuentas & e-info, e-mediación, e-foros & Correo electrónico, Facebook, Twitter, Youtube, blogs \\
\hline Evaluar la rendición de cuentas & e-info, e-mediación, e-referéndum & $\begin{array}{l}\text { Facebook, Twitter, Youtube, blogs, softwares } \\
\text { participativos }\end{array}$ \\
\hline
\end{tabular}

Fuente: Elaboración propia a partir de Macintosh, Coleman y Lalljee (2005), Molinari (2010) y Lindner y Aichholzer (2020).

El presupuesto participativo electrónico es una de las variedades de la e-participación que exige el más amplio espectro de la e-democracia. Como es sabido (Aguirre, 2014), el presupuesto participativo electrónico posee prerrogativas y alcances que lo muestran como un caso ejemplar de la e-democracia, pues involucra desde la e-información para establecer las condiciones de las e-convocatorias, hasta los medios de la e-transparencia y e-rendición de cuentas evaluativa, pasando por casi todo el espectro de herramientas electrónicas y mecanismos de participación ciudadana. 


\section{Conclusiones}

El dilema general: la emergencia de una democracia por y para la era digital, o la mera aportación de las redes digitales para la democracia existente, se traduce en la versión electrónica que implica la transición hacia un régimen democrático. La nueva realidad democrática pretende superar los déficits hasta ahora padecidos por los regímenes políticos y aprovechar algunas aportaciones electrónicas para cambiar o complementar la constitución de estructuras e instrumentos democráticos, el funcionamiento de sus instituciones y los procedimientos establecidos.

La mutua influencia y las recíprocas implicaciones entre los regímenes políticos y los avances tecnológicos han quedado de manifiesto en el desarrollo ecléctico de la democracia electrónica (Aguirre, 2020). Ni la cibernética existe pura en el vacío, ni la democracia se encarna incólume de todo tipo de intereses y diferencias de clase. En términos más clásicos cabe señalar: el fin operis de las TIC no es idéntico al fin operantis, tampoco el fin operis y operantis de la democracia; pero los cuatro vértices no están desligados. La vinculación causa que las TIC no sean políticamente neutrales, ni la democracia totalmente indiferente a las TIC; por esto, hay suficientes razones para el rechazo a un dilema en disyuntiva excluyente y, en consecuencia, el abandono a las dicotomías de ciberoptimistas y ciberpesimistas de una e-democracia desde «arriba» o «abajo», de a priori o a posteriori entre la pretensión prescriptiva y la constatación descriptiva de la democracia. Por ende, asistimos a mezclas, modelos y clasificaciones en que emerge o se constata la e-democracia sesgada por preconcepciones del quehacer político.

La conclusión general asevera que la innovación de las TIC provoca una mayor horizontalización de la democracia. Aunque las innovaciones, como la historia demuestra, se crean para obtener soluciones, también acarrean nuevas problemáticas. Como, por ejemplo, la información falsa (fake news) y la saturación de información que debilitan la capacidad cognitiva opacan la transparencia y promueven conductas reaccionarias al simple agrado y disgusto en vez de la construcción democrática. $\mathrm{O}$ la brecha digital, que es la punta del iceberg que anuncia y provoca brechas estructurales: sociales, económicas, políticas y educacionales. O también el debilitamiento de las mediaciones institucionales, de partidos políticos, legislaturas y organismos públicos autónomos por medio de ataques hacker con bots y trolls. Como es sabido, la recurrencia al hackeo por Anonymous ha invadido y dañado a consorcios comerciales, corporaciones financieras y Gobiernos, además de promover acciones subversivas, bloqueos y sabotajes, llegando a invadir parcialmente las páginas electrónicas de algunos parlamentos. Otras dificultades están en los algoritmos cibernéticos (por ejemplo, el PageRank, utilizado por Google) que filtran y jerarquizan la información arrojada en las búsquedas provocando la fragmentación del público y más. Estas di- 
ficultades constituyen el reto endógeno de la democracia electrónica que merece una investigación más allá del análisis comprometido en este texto.

\section{Referencias}

AguirRe, Jorge (2014). «Una contribución de internet contra el déficit democrático: Prerrogativas, riesgos, límites y alcances del Presupuesto Participativo electrónico». Revista Internacional de Pensamiento Político, 9: 231-247. Disponible en bit. $\mathrm{ly} / 3 \mathrm{fx} 4 \mathrm{fBm}$.

-. (2017). Introducción a la democracia líquida. Ciudad de México: LXIII Legislatura.

-. (2018). «Pro et contra de la democracia electrónica». En Luis Mañas, Sendy Meléndez y Estrella Martínez (coordinadores), La comunicación ante el ciudadano (pp. 15-30). Madrid: Gedisa.

-. (2019). «Democracia líquida: La opción de las TIC para incorporar la participación ciudadana en instituciones representativas». Athenea Digital, 19 (2): e2212. DOI: $10.5565 / \mathrm{rev} /$ athenea.2212.

-. (2020). «El desarrollo histórico de la democracia electrónica y sus implicaciones políticas». Trayectorias, 22 (50): 55-79. Disponible en bit.ly/34sA1ce.

Baratta, Alessandro (1997). «Política criminal: Entre la política de seguridad y la política social en países con grandes conflictos sociales y políticos». En Elías Carranza (coordinador), La situación del delito y de la seguridad de los habitantes en América Latina (pp. 80-98). Ciudad de México: Instituto Nacional de Ciencias Penales y Siglo XXI.

BARBER, Benjamín (1998). «Which technology and which democracy?». Conferencia Democracy and Digital Media, Boston, 6 de diciembre de 1998. Disponible en https://bit.ly/3vAVz2q.

Bauman, Zygmunt (2000). Liquid modernity. Cambridge: Polity Press.

Bellamy, Craig (2000). «Modelling electronic democracy: Towards democratic discourses for an information age». En Jens Hoff, Ivan Horrock y Pieter Tops (editores), Democratic governance and new technology (pp. 34-55). Londres: Routledge.

BlaUg, Ricardo (2002). «Engineering democracy». Political Studies, 50: 102-116. DOI: 10.1111/1467-9248.00361.

Buum, Christian y Christina Isabel Zuber (2016). «Liquid democracy: Potentials, problems, and perspectives». The Journal of Political Philosophy, 2 (24): 162-182. DOI: 10.1111/jopp.12065.

BRINTON, Crane (1938). The anatomy of revolution. Nueva York: Harper \& Brothers.

Cairo Carou, Heriberto (2002). Democracia digital, límites y oportunidades. Madrid: Trotta.

Coleman, Stephen y Donald Norris (2005). A new agenda for e-democracy. Oxford: Oxford Internet Institute. 
Corval, Xavier (2010). «Desafíos y logros de la democracia electrónica». En Democracia electrónica: ¿Qué desafíos para América Latina? Santiago: Aún Creemos en los Sueños.

Cotarelo, Ramón (2002). «¿Democracia electrónica vs. democracia deliberativa». En Heriberto Cairo (compilador), Democracia digital, límites y oportunidades (pp. 9-12). Madrid: Trotta.

DAHLBERG, Lincoln (2011). «Re-constructing digital democracy: An outline of four positions». New Media and Society, 13 (6): 855-872. DOI: 10.1177/1461444810389569.

Díez RodríGuez, Ángeles (2003). «Ciudadanía cibernética: La nueva utopía tecnológica de la democracia». En Jorge Benedicto y María Luz Morán (editores), Aprendiendo a ser ciudadanos: Experiencias sociales y construcción de la ciudadanía ente los jóvenes (pp. 193-217). Madrid: Instituto de la Juventud.

Feenstra, Ramón y Andreu Casero-Ripollés (2014). «Democracy in the digital communication environment: A typology proposal of political monitoring processes». International Journal of Communication, 8: 1.448-2.468. Disponible en bit. ly/3uw1BQr.

Ford DeZA, Elaine (2019). El reto de la democracia digital: Hacia una ciudadanía interconectada. Lima: Jurado Nacional de Elecciones, Oficina Nacional de Procesos Electorales, Konrad-Adenauer-Stiftung y Democracia \& Desarrollo Internacional.

Fraser, Bruce (1990). «Perspectives on politeness». Journal of Pragmatics, 14 (2): 219236. DOI: 10.1016/0378-2166(90)90081-N.

FunG, Archon, Hollie Russon-Gilman y Jennifer Shkabatur (2013). «Six models for the internet \& politics». International Studies Review, 15: 30-47. DOI: 10.1111/misr.12028.

García Canclini, Néstor (1995). Consumidores y ciudadanos: Conflictos multiculturales de la globalización. Ciudad de México: Grijalbo.

García Guitián, Elena (2016). «Democracia digital: Discursos sobre participación ciudadana y TIC». Revista de Estudios Políticos, 173: 169-193. DOI: 10.18042/cepc/ rep.173.05.

Gerbaudo, Paolo (2019). The digital party: Political organization and online democra$c y$. Londres: Pluto.

Hagen, Martin (1997). «A typology of electronic democracy». Disponible en bit. ly/2SE4521.

Harto de Vera, Fernando (2006). «Tipologías y modelos de democracia electrónica». Revista de Internet, Derecho y Política, 2: 32-44. Disponible en bit.ly/3fx86hO.

Harvey, David (2012). Rebel cities. Londres: Verso.

Hindman, Matthew (2009). The myth of digital democracy. Princeton: Princeton University Press.

Kampen, Jarl y Kris Snijkers (2003). «E-democracy: A critical evaluation of the ultimate e-dream». Social Science Computer Review, 21 (4): 491-496. DOI: 10.1177/0894439303256095. 
Kersting, Norbert (2012). Electronic democracy. Opladen: Verlag Barbara Budrich. KuHn, Ingrid (2013). Liquid democracy: Chancen und Grenzen einer neuen Form der Bürgerbeteiligung. Fráncfort: Europa-Universität Viadrina Frankfurt.

Kurban, Can, Ismael Peña-López y María Haberer (2016). «What is technopolitics? A conceptual scheme for understanding politics in the digital age». En Building a European digital space: 12th International Conference on Internet, Law and Politics. Barcelona: Univesitat Oberta de Catalunya, Huygenes.

LaNG, Mabel y John Mck. Camp II (2004). «The Athenian citizen: Democracy in the Athenian agora». Volumen 1. Atenas: American School of Classical Studies.

Linares, Sebastián (2019). Democracia participativa epistémica. Madrid: Marcial Pons.

LINDNER, Ralf y Georg Aichholzer (2020). «E-democracy: Conceptual foundations and recent trends». En Leonhard Hennen, Ira Van Keulen, Iris Korthagen, Georg Aichholzer, Ralf Lindner y Rasmus Ojvind Nielsen (editores), European e-democracy in practice. Berlín: Springer.

Lindner, Ralf, Georg Aichholzer y Leonhard Hennen (2016). «Electronic democracy in Europe: An introduction». En Ralf Lindner, Georg Aichholzer y Leonhard Hennen (editores), Electronic democracy in Europe: Prospects and challenges of epublics, e-participation and e-voting. Berlín: Springer.

LINDNER, Ralf, Bernd Beckert, Georg Aichholzer, Stefan Strauß y Leonhard Hennen (2010). E-democracy in Europe: Prospects of internet-based political participation. Bruselas: European Parliament, STOA.

Macintosh, Ann (2004). «Characterizing e-participation in policymaking». Proceedings of the 37th Hawaii International Conference on System Sciences, 1-10.

Macintosh, Ann, Stephen Coleman y Mansur Lalljee (2005). E-methods for public engagement: Helping local authorities communicate with citizens. Bristol: City Council.

MARShall, Alfred (1997). «Ciudadanía y clase social». Revista Española de Investigaciones Sociológicas, 79: 297-344. Disponible en bit.ly/3p6acbe.

Mendoza, Nicolas (2015). «Liquid separation: Three fundamental dimensions within LiquidFeedback and other voting technologies». eJournal of eDemocracy \& Open Government, 7 (2): 45-58. DOI: 10.29379/jedem.v7i2.408.

Molinari, Francesco (2010). «Thrilled by the tools, chilled by the figures: How an "e" can really make the difference in political participation». En Sandeep Krishnamurthy, Gurmit Singh y Maggie McPherson (editores), Proceedings of the IADIS International Conference: e-Democracy, Equity and Social Justice. Freiburg.

Morozov, Evegny (2015). La locura del solucionismo tecnológico. Buenos Aires: Katz. Noveck, Beth Simone (2009). Wiki government: How technology can make government better, democracy stronger, and citizens more powerful. Washington, D. C.: Brookings Institution Press. 
Oвer, Josiah (2008). Democracy and knowledge: Innovation and learning in classical Athens. Princenton: Princenton University Press.

Pärivärinta, Tero y Øystein Saebo (2006). «Models of e-democracy». Communications of the Association for Information Systems, 17 (1): 818-840. DOI: 10.17705/1CAIS.01737.

PÉrez-Luño, Antonio-Enrique (2014). «Teledemocracia, ciberciudadania y derechos humanos». Revista Brasileira de Políticas Públicas, 4 (2): 8-46. DOI: 10.5102/rbpp. V4i2.2835.

Prats, Joan y Óscar del Álamo (2003). Democracia electrónica: Concepto, tipos y posicionamientos. Barcelona: Instituto Internacional de Gobernabilidad de Cataluña.

SARTORI, Giovanni (1987). Democrazia: Cosa é. Milán: Rizzoli.

SCHARPF, Fritz (1999). Regieren in Europa: Effektiv und demokratisch? Fráncfort: Campus.

Schudson, Michel (2006). «New technologies and not-so-new democracies». MedieKultur, 22 (40): 1-9. DOI: 10.7146/mediekultur.v22i40.1284.

Subirats, Joan (2002). «Los dilemas de una relación inevitable: Innovación democrática y tecnologías de la información y de la comunicación». En Heriberto Cairo (compilador), Democracia digital: Límites y oportunidades. Madrid: Trotta.

Szoka, Berin y Adam Marcus (2010). The next digital decade: Essays on the future of the internet. Washington D. C.: Tech Freedom.

Trechsel, Alexander, Raphael Kies, Fernando Mendez y Philippe Schmitter (2004). Evaluation of the use of new technologies in order to facilitate democracy in Europe. Luxemburgo: European Communities.

Tsatsou, Panayiota (2014). Internet studies: Past, present, future directions. Farnham: Ashgate.

Txopitea, Marko (2011). «Política 2.». En Gunnar Wolf y Alejandro Miranda (coordinadores), Construcción colaborativa del conocimiento. Ciudad de México: UNAM, Instituto de Investigaciones Económicas.

VAN DijK, Jan (2000). «Models of democracy and concepts of communication». En Kenneth Hacker y Jan Van Dijk, Digital democracy. Londres: Sage.

VAN DiJK, Jan y Kenneth Hacker (2018). Internet and democracy in the network society. Nueva York: Routledge.

VedEL, Thierry (2003). «Lidee de democratie electronique origines, visions, questions». En Perrineau Pascal (director), Paru dans Le désenchantement démocratique. La Tour d'Aigues: Editions de l'Aube.

Weare, Christopher, Juliet A. Musso y Matthew Hale (1999). «Electronic democracy and the diffusion of municipal web pages in California». Administration \& Society, 31 (1): 3-27. DOI: 10.1177/009539999400935475. 


\section{Sobre el autor}

Jorge Francisco Aguirre Sala es doctor y licenciado en Filosofía por la Universidad Iberoamericana de México. Se encuentra adscrito al Instituto de Investigaciones Sociales de la Universidad Autónoma de Nuevo León, México. Su correo electrónico es jorgeaguirresala@hotmail.com. (DD https://orcid.org/oooo-0002-5805-4082. 


\title{
REVISTA CHILENA DE DERECHO Y TECNOLOGÍA
}

La Revista de Chilena de Derecho y Tecnología es una publicación académica semestral del Centro de Estudios en Derecho Informático de la Facultad de Derecho de la Universidad de Chile, que tiene por objeto difundir en la comunidad jurídica los elementos necesarios para analizar y comprender los alcances y efectos que el desarrollo tecnológico y cultural han producido en la sociedad, especialmente su impacto en la ciencia jurídica.

\author{
EDITOR GENERAL \\ Daniel Álvarez Valenzuela \\ (dalvarez@derecho.uchile.cl) \\ SITIO WEB \\ rchdt.uchile.cl \\ CORREO ELECTRÓNICO \\ rchdt@derecho.uchile.cl \\ LICENCIA DE ESTE ARTÍCULO \\ Creative Commons Atribución Compartir Igual 4.o Internacional
}

\begin{abstract}
La edición de textos, el diseño editorial
y la conversión a formatos electrónicos de este artículo

estuvieron a cargo de Tipográfica

(www.tipografica.io).
\end{abstract}

